\title{
Comparative Study of OFDI Efficiency in China Based on SBM-Model
}

\author{
Sen Huang, Yu Chen* and Xiaoming Guo \\ Research Center of National Economy and International Business, Sichuan International Studies University, 33 \\ Zhuangzhi Road, Shapingba District, Chongqing, China \\ *Corresponding author. Email: claireccy@163.com
}

\begin{abstract}
Since the "Belt\&Road" was put forward, China has always been committed to building a green the "Belt\&Road". Based on the panel data of China's direct investment in 30 key countries along the "Belt\&Road" from 2009 to 2018 , this paper systematically analyzes the efficiency of green investment from multiple dimensions by using SBM-undesirable model. The research shows that the efficiency of China's green investment in countries along the "Belt\&Road" is generally good, but there are big internal differences among the host countries. In recent years, the rising pure technical efficiency of green investment has largely compensated for the relatively low scale efficiency of green investment. The research in this paper provides evidence for understanding the relationship between China's "the belt and road initiative" initiative and the green sustainable development of the host country, and provides theoretical support for countries to create a harmonious international investment environment.
\end{abstract}

Keywords: OFDI efficiency, SBM-Model, The Belt and Road, Green investment.

\section{INTRODUCTION}

With the smooth progress of the "Belt\&Road" Initiative (The "Belt\&Road" Initiative, hereinafter referred to as BRI), the economic and trade cooperation between China and the route countries continues to deepen. Until March 2019, 172 countries or international organizations have joined the BRI. It has hugely promoted the economic contacts between China and relevant countries and pushed forward the economic cooperation. Under this background, from year 2006 to 2018, the average annual growth rate of the total investment of Chinese enterprises in the BRI route countries reached $5.6 \%$, and the growth rate in 2018 even reached $8.9 \%$. Meanwhile, since the BRI International Cooperation Summit Forum was held in Beijing in 2017, the green BRI has once again become a global hot spot. The green BRI aims to "optimize the layout of industry and energy, promote the construction of green infrastructure, strengthen green trade and green investment, and improve the green financial system". So how to effectively promote the construction of the green BRI? This paper holds that the BRI always adheres to the concept of green development. And green investment is a key link in realizing the construction of a green BRI. Choosing green investment efficiency as the breakthrough point, it is necessary to examine in detail the interaction mechanism of bilateral investment between China and countries along the BRI. Specifically, this paper will introduce the green investment efficiency index to measure China's investment situation along the BRI from perspectives of green sustainability and "efficient" foreign investment.

\section{ESTIMATION OF GREEN INVESTMENT EFFICIENCY}

\subsection{SBM Model}

At present, the general DEA model is commonly used in the calculation of investment efficiency in academic circles at home and abroad. (Tian Z, 2016; Xue A W, 2017). However, the general DEA model cannot effectively bring the unexpected output into the green investment efficiency analysis system, which directly affects the theoretical accuracy of the green investment efficiency evaluation. To solve this problem, Tone (2001) proposed a non-radial and non-angular SBM-undesirable model to introduce unexpected output to measure green efficiency. The green investment efficiency includes expected output and unexpected output. Therefore, when investigating the green 
investment efficiency of China to countries along the "Belt\&Road", it is necessary to build a production possibility set including input, expected output and unexpected output. It is assumed that DUM unit is n, input element is $\mathrm{m}$, expected output is $\mathrm{S} 1$, and unexpected output is $\mathrm{S} 2$ in production decision system. The vectors are $\mathrm{x} \in \mathrm{R}_{\mathrm{m}}, \mathrm{y}^{\mathrm{g}} \in \mathrm{R}_{\mathrm{s} 1}, \mathrm{y}^{\mathrm{b}} \in \mathrm{R}_{\mathrm{s} 2}$; The matrix $\quad X=\left(x_{i j}\right) \in R_{m * n}, Y^{g}=\left(y_{i j}^{g}\right) \in R_{s 1 * n}, Y^{b}=$ $\left(y_{i j}^{b}\right) \in R_{s 2 * n}$. Assuming $x>0, y g>0, y b>0$, and the production possibility set is a closed set and a bounded set, the input and output can be disposed freely, and assuming that the expected output and the unexpected output are zero combined and the output joint is weak disposable, the model is expressed as follows:

$\mathrm{G}=\left\{\left(\mathrm{x}, \mathrm{y}^{\mathrm{g}}, \mathrm{y}^{\mathrm{b}}\right) \mid \mathrm{x} \geq \mathrm{X} \lambda, \mathrm{y}^{\mathrm{g}} \leq \mathrm{Y}^{\mathrm{g}} \lambda, \mathrm{y}^{\mathrm{b}}=\mathrm{Y}^{\mathrm{b}} \lambda, \sum_{\mathrm{i}=1}^{\mathrm{n}} \lambda, \lambda \geq 0\right\}$

When $\sum_{0}^{\mathrm{n}} \lambda \neq 1$, the model is constant in scale reward; And when $\sum_{0}^{\mathrm{n}} \lambda=1$, the model is variable in scale reward. Then, according to the SBM model proposed by Tone (2001), the linear programming equation of a specific DUM is firstly constructed:

$$
\min \rho^{*}=1-\frac{1}{m} \sum_{k=1}^{m} s_{k}^{-} / x_{i 0} / 1+\frac{1}{s_{1}+s_{2}}\left(\sum_{i=1}^{s_{1}} \frac{s_{i}^{g+}}{y_{i 0}^{g}}+\sum_{r=1}^{s_{2}} \frac{s_{r}^{b+}}{y_{i 0}^{b}}\right)
$$$$
\text { s.t. }\left\{\begin{array}{l}
x_{0}=X \lambda+s^{-} \\
y_{0}^{g}=Y^{g} \lambda-s^{g+} \\
y_{0}^{b}=Y^{b} \lambda+s^{b+} \\
\lambda, s^{-}, s^{g+}, s^{b+} \geq 0
\end{array}\right.
$$

In formula (2), the subscripts of $\mathrm{x}$ and $\mathrm{y}$ are 0 , which means that when the DUM is taken, the specific value $\lambda$ is weight, $S$ represents the relaxation variable, $S$ represents the input relaxation variable, $S+$ represents input relaxation variable, $\rho$ is efficiency value, and the value ranges from 0 to 1 .

Finally, this paper introduces undesirable output by splitting y0 in formula (2), that is, for a specific DMU, there are: $\mathrm{x}_{0}=\mathrm{X} \lambda+\mathrm{s}^{-}, \mathrm{y}_{0}^{\mathrm{g}}=\mathrm{Y}^{\mathrm{g}} \lambda-\mathrm{s}^{\mathrm{g}+}, \mathrm{y}_{0}^{\mathrm{b}}=\mathrm{Y}^{\mathrm{b}} \lambda+$ $\mathrm{s}^{\mathrm{b}+}$, and the formula is:

$$
\begin{aligned}
& =1-\frac{1}{\mathrm{~m}} \sum_{\mathrm{i}=1}^{\mathrm{m}} \mathrm{s}_{\mathrm{i}}^{-} / \mathrm{x}_{\mathrm{i} 0} / 1+\frac{1}{\mathrm{~s}_{1}+\mathrm{s}_{2}}\left(\sum_{\mathrm{r}=1}^{\min \rho^{*}} \frac{\mathrm{s}_{\mathrm{r}}^{\mathrm{g}+}}{\mathrm{y}_{\mathrm{r} 0}^{\mathrm{g}}}+\sum_{\mathrm{r}=1}^{\mathrm{s}_{2}} \frac{\mathrm{s}_{\mathrm{r}}^{\mathrm{b}+}}{\mathrm{y}_{\mathrm{r} 0}^{\mathrm{b}}}\right) \\
& \text { s.t. }\left\{\begin{array}{c}
\mathrm{x}_{0}=\mathrm{X} \lambda+\mathrm{s}^{-} \\
\mathrm{y}_{0}^{\mathrm{g}}=\mathrm{Y}^{\mathrm{g}} \lambda-\mathrm{s}^{\mathrm{g}+} \\
\mathrm{y}_{0}^{\mathrm{b}}=\mathrm{Y}^{\mathrm{b}} \lambda+\mathrm{s}^{\mathrm{b}+} \\
\lambda, \mathrm{s}^{-}, \mathrm{s}^{\mathrm{g}+}, \mathrm{s}^{\mathrm{b}+} \geq 0
\end{array}\right.
\end{aligned}
$$

In formula (3), $\lambda$ is the weight, $s^{-}$represents the input relaxation variable, $s^{g+}$ represents the expected output slack variable, and $s^{b+}$ represents the unexpected output relaxation variable. $\rho^{*}$ is the production efficiency of each DUM when the unexpected output is considered. It is clearly that the linear programming model of formula (3) brings input, expected output and unexpected output into the objective function at the same time, which solves the problems faced by traditional DEA well. Therefore, this paper will choose this model to measure the efficiency of China's green investment in countries along the "Belt\&Road".

\subsection{Index System}

On the selection of input index system, this paper, referring to the research experience of some scholars, takes China's direct investment stocks in the host country and the total labor force of the host countries as input items. On the selection of output index system, through the analysis of $\mathrm{Hu}$ and Jin (2017) and other scholars, it is concluded that China's investment in countries along the "Belt\&Road" can mainly impact the host country's economic level, the living standard of people, and the bilateral trade volume. Therefore, this paper selects the GDP of the host country and the adjusted net national income per capita of the host country's nationals, and the total net trade in goods and services between the host country and China as the expected output. All output indicators are converted into 2010 constant US dollars. According to the domestic and foreign practice of measuring green investment efficiency, this paper selects the host country's $\mathrm{CO} 2$ emissions in the current year as the unexpected output index. The specific index system is as follows.

Table 1. Descriptive statistical analysis results of index system

\begin{tabular}{cccc}
\hline & Variables & $\begin{array}{c}\text { The number } \\
\text { of samples }\end{array}$ & Units \\
\cline { 2 - 4 } $\begin{array}{c}\text { Input index } \\
\text { (X) }\end{array}$ & OFDI stocks & 30 & $\begin{array}{c}\text { Ten } \\
\text { thousand } \\
\text { USD }\end{array}$ \\
& $\begin{array}{c}\text { Total labor force of the host } \\
\text { countries }\end{array}$ & 30 & $\begin{array}{c}\text { One } \\
\text { thousand } \\
\text { people }\end{array}$ \\
\cline { 2 - 4 } & $\begin{array}{c}\text { GDP (2010 USD constant } \\
\text { price) }\end{array}$ & 30 & USD \\
Output & $\begin{array}{c}\text { Adjusted net national } \\
\text { income per capita (2010 } \\
\text { USD constant price) }\end{array}$ & 30 & USD \\
& $\begin{array}{c}\text { Total net trade in goods and } \\
\text { services between the host } \\
\text { country and China } \\
\text { CO2 emission of host } \\
\text { country }\end{array}$ & 30 & $\begin{array}{c}\text { Million } \\
\text { USD }\end{array}$ \\
& $\quad 30$ & Kt \\
\hline
\end{tabular}


Table 2. Mean Efficiency of Green Investment

\begin{tabular}{|c|c|c|c|c|c|c|c|}
\hline & Comp & Pure & Scale & Country & Comp & Pure & Scale \\
\hline Lithuania & 5.40 & 5.84 & 0.93 & Turkey & 0.53 & 1.08 & 0.57 \\
\hline Greece & 4.93 & 7.97 & 0.69 & Saudi Arabia & 0.52 & 0.53 & 0.98 \\
\hline Estonia & 4.81 & 4.98 & 0.92 & Albania & 0.51 & 1.00 & 0.51 \\
\hline Belgium & 2.61 & 1.00 & 0.20 & Hungary & 0.35 & 0.37 & 0.94 \\
\hline New Zealand & 2.21 & 3.21 & 0.76 & Romania & 0.34 & 0.37 & 0.92 \\
\hline Slovakia & 1.35 & 1.59 & 0.89 & Ukraine & 0.32 & 1.13 & 0.38 \\
\hline $\begin{array}{c}\text { Czech } \\
\text { Republic }\end{array}$ & 1.34 & 1.59 & 0.85 & Thailand & 0.32 & 0.46 & 0.71 \\
\hline Vietnamese & 1.17 & 1.72 & 0.71 & Bulgaria & 0.28 & 0.39 & 0.83 \\
\hline Australia & 1.03 & 1.04 & 1.00 & Kazakhstan & 0.23 & 0.24 & 0.98 \\
\hline Singapore & 1.00 & 1.00 & 1.00 & Russia & 0.22 & 0.26 & 0.86 \\
\hline Brunei & 1.00 & 1.00 & 1.00 & Belarus & 0.19 & 0.26 & 0.77 \\
\hline France & 1.00 & 1.00 & 1.00 & India & 0.13 & 1.06 & 0.14 \\
\hline Germany & 0.98 & 1.00 & 0.98 & Sri Lanka & 0.11 & 0.21 & 0.58 \\
\hline Malaysia & 0.78 & 0.86 & 0.90 & Indonesia & 0.11 & 0.18 & 0.64 \\
\hline Poland & 0.60 & 1.27 & 0.55 & Pakistan & 0.04 & 0.04 & 0.96 \\
\hline
\end{tabular}

It should be noted that the BRI is taken as the research background and the selected time range is from year 2009 to 2018. Due to the serious data shortage in some countries, 30 route countries of the "Belt\&Road" are selected as the research objects through repeated comparison and screening. It Includes 25 countries that have already joined the initiative, such as Ukraine, Russia, Greece, Slovakia, Romania, Czech Republic, Hungary, Poland, Lithuania, Bulgaria, Albania, Estonia, Singapore, Kazakhstan, Indonesia, Malaysia, Thailand, Vietnam, Brunei, Belarus, Pakistan, Sri Lanka, Turkey, Saudi Arabia and New Zealand. Another 5 countries that have close contacts with China due to the construction of the BRI are Belgium, Australia, Germany, France and India. These 30 countries basically cover the area of the "Belt\&Road" route. In addition, the data needed for this study are all from the DataBank database of the World Bank, the UN Comtrade database of the United Nations and the corresponding national statistical yearbooks. Some incomplete data are supplemented by the data-smoothing method or data-interpolation method.

At the same time, studies have shown that judging whether China's foreign investment is effective should pay more attention to whether investment can directly promote the promotion of bilateral trade flows and produce obvious trade effects. Therefore, this paper draws lessons from the research of Chai Q C and $\mathrm{Hu} T$ $Y$ (2012) and chooses the total net trade of goods and services between the host countries and China as one of the output indicators.

According to the Vision and Action of Promoting the Co-construction of the Silk Road Economic Belt and the 21st Century Maritime Silk Road, in the investment and trade of the BRI, the concept of ecological civilization should be highlighted to jointly build the Green Silk Road. Therefore, this paper selects the CO2 emission of the host countries in the current year as the unexpected output index of China's foreign investment efficiency.

\section{RESULTS AND DISCUSSION}

Based on MAXDEA7.0 pro software system, this paper calculates the green investment efficiency of China in 30 countries along the "Belt\&Road" from 2009 to 2018. It specifically includes three aspects: comprehensive efficiency of green investment, pure technical efficiency of green investment and scale efficiency of green investment, in which comprehensive efficiency of green investment equals the pure technical efficiency of green investment multiplied by the scale efficiency of green investment.

It should be noted that when the value of green investment efficiency is greater than or equal to 1 , it means that the green investment efficiency has passed the effectiveness test. When the value is less than 1 , it indicates that China's investment in the host country is ineffective under environmental constraints. Table 2 reflects the average of the three efficiencies in 30 countries from 2009 to 2018.

According to the results in Table 2, the comprehensive efficiency of 12 countries, such as such as Singapore, Vietnam, Estonia and so on, has been effective in the past ten years, while the remaining 18 countries are ineffective to some extent.

Specifically, 10 countries such as Kazakhstan, Russia and Belarus have a pure technical efficiency value lower than 0.5 . The results show that with the 
further development of the "Belt\&Road", the decision-making of most domestic investors can adapt to the market environment of countries along the route and the utilization rate of investment in China by the host country is relatively high. At the same time, the pure technical efficiency of the remaining 10 countries is relatively low, which indicates that China still has much room to adjust its investment decisions and technologies to adapt to the local market environment of the host countries.

On the premise of considering the scale factor, the scale of China's green investment in 30 countries was significantly ineffective during the inspection period. Under the environmental constraints, the overall utilization rate of China's investment capital in 30 countries along the "Belt\&Road" was not high. And there was a big difference between the nominal investment amount and the actual use amount, with a large amount of investment redundancy and waste of resources.As far as countries are concerned, except Brunei, France, Australia and other three countries, the scale efficiency of green investment was effective, and the other 27 countries waste the investment capital of China to a certain extent. Among them, Belgium, Ukraine, India, Poland, Albania, Turkey and Sri Lanka had lower scale efficiency than other countries, and there was much room for improvement.

In conclusion, during the inspection period, China's comprehensive efficiency of green investment in countries along the "Belt\&Road" was partially effective, and there were big differences within 30 countries. Only 12 countries such as Czech Republic were effective, and there were still 18 countries whose comprehensive efficiency of green investment was ineffective, with invalid countries accounting for about $60 \%$ of the total sample. In recent years, with the development of BRI, the pure technical efficiency and scale efficiency of green investment in host countries have gradually increased, which can offset the ineffectiveness of green investment in host countries to a certain extent.

\section{CONCLUSIONS AND SUGGESTION}

Using the big data of China's investment along the"Belt\&Road", from 2009 to 2018, this paper systematically calculates the efficiency level of China's green investment in relevant countries. The results show that during 2009 to 2018, China's green investment efficiency in countries along the BRI is partly good. And there are big internal differences among host countries. However, the reasons for this result are different: Ukraine, India, Turkey, Poland and so on, because the scale efficiency of green investment is significantly lower than other countries, the comprehensive efficiency of green investment is invalid; Some countries, such as Kazakhstan, Sri Lanka,
Russia, Belarus, Pakistan and so on, may because the lower pure technical efficiency of green investment.

Based on the above conclusions, this paper puts forward the following two suggestions.

First, since the "Belt \& Road" route countries have obvious gaps in green investment efficiency, China needs to carry out targeted foreign investment activities. For this reason, when China invests abroad, it should first choose countries with high green investment efficiency and relatively perfect investment environment, such as Singapore and Australia. Faced with countries with low efficiency of green investment, such as Ukraine, Russia, Belarus, Sri Lanka and other countries, China should choose investment decisions and technologies suitable for the host country to adapt to the local market environment so as to achieve the goal of improving the efficiency of green investment.

At the same time, the green development is very important in BRI, and China has always adhered to green development in practice. Therefore, when carrying out foreign investment activities, China should try its best to select projects and technologies that are in line with the national conditions of the host country, adjust measures to local conditions, and improve the green efficiency of investment. At the same time, China should promote green cooperation in infrastructure, product trade, financial services and other related fields, and enhance the overall green investment efficiency of the "Belt\&Road".

\section{ACKNOWLEDGEMENTS}

This work was supported by Science And Technology Project of Chongqing Education Commission (Grants No. KJQN201900901); Sichuan International Studies University's School-level Scientific Research Project (Grants No. SISU2019039); Sichuan International Studies University's Graduate Research Innovation Project in 2020 (Grants No. SISU2020YY06).

\section{REFERENCES}

[1] Eyraud L, Clements B and Wane A 2013 Green investment: trends and determinats Energy. Policy 60 852-865.

[2] Tian Z and Xu DM 2016 China's comprehensive efficiency evaluation of OFDI in the "Belt\&Road" key countries_-based on super-efficiency DEA and malmquist index Inquiry Econ. Issue. 6 7-14

[3] Xue A W 2017 The influence of international direct investment and import and export on technical efficiency — An empirical analysis 
based on China's provincial panel data World Econ. Study 2 78-87+136

[4] Tone Z F and Khan M S 2001 A slacks-based measure of efficiency in data envelopment analysis EUR. J. O. R. 130 498-509.

[5] Chai Q C and Hu T Y 2012 Research on the trade effect of China's foreign direct investment based on the investigation of investment differences between ASEAN and EU. World Econ. R. 10 64-69+89

[6] Hu H, Jin Z and Xie J 2017 Efficiency estimation of china's outward foreign direct investment and its influencing factors World. Econ. Study $\mathbf{1 0}$ 45-54+136 